\title{
METODOLOGIA DE ENSINO POR PROJETOS NA PRÁTICA PEDAGÓGICA
}

\author{
Susana Marília Barbosa Galvão*
}

\section{Resumo}

Este artigo teve como objetivo descrever a eficácia da metodologia de ensino por projetos na prática de sala de aula, beneficiando professores e alunos no âmbito da aprendizagem escolar. É um artigo bibliográfico de revisão entendendo por metodologia de ensino os encaminhamentos educativos da prática pedagógica, os quais se constituem em um conjunto de ideias e teorias educativas. Sendo assim, metodologia de ensino refere-se aos encaminhamentos educativos que o professor utiliza visando auxiliar seu aluno na produção do conhecimento. Em relação à utilização de projetos no ensino, eles partem de uma necessidade real do aluno e constituem um elemento fundamental do processo de planejamento. $O$ projeto permite prever os processos de uma atividade de maneira adequada, estimar custos, recursos, viabilizar o tempo disponível, e realizar uma posterior avaliação, comparando alcance dos objetivos e metas.

Palavras-chave: Metodologia de Projetos. Professor. Aluno

\section{INTRODUÇÃO}

A dinâmica de um bom trabalho pedagógico na sala de aula entre professor e aluno é um constante desafio entre os educadores. Os fatores condicionadores da prática pedagógica são vários, desde os problemas gerais da sociedade até aqueles relacionados à estrutura e funcionamento da escola, passando por aqueles diretamente ligados à carreira e à formação dos professores.

Ao lado destas dificuldades naturais, ganhou força em tempos recentes uma percepção estereotipada de alguns educadores sobre os alunos que freqüentam as escolas públicas e que têm sido, com freqüência, alvo de expressões genéricas do

\footnotetext{
* Graduada em Pedagogia Pela PUC/MG. Doutoranda em Ciências da Educação pela Facultad Interamericana de Ciencias Sociales-FICS. Email: susi.barbosa@hotmail.com
} 
tipo: "os alunos são fracos", "estão despreparados", "são desinteressados", "não querem nada".

Esta percepção tem interferido negativamente na relação pedagógica e é indispensável que ela seja superada e que em seu lugar a Escola assuma a ideia de que são justamente estes os alunos que mais precisam de uma boa formação, de um ensino que se constitua em instrumental básico de sobrevivência na prática social.

Preparar o aluno para um processo de educação permanente é compromisso da educação básica, mas para que aconteça o ensino e a aprendizagem de metodologias precisam priorizar as estratégias e a comprovação de hipóteses na construção do conhecimento, de argumentos que favoreçam o espírito crítico. Necessário se faz uma dinâmica de ensino que favoreça as potencialidades individuais e coletivas.

\section{PLANEJAMENTO NA PRÁTICA PROFISSIONAL}

O planejamento segundo Carvalho (1979), assume tamanha importância a ponto de se constituir como objeto de teorização e podem ser encontrados em várias teorias do planejamento. Uma das mais modernas vincula-se à teoria geral dos sistemas. Assim, "envolve quatro elementos necessários e suficientes para a sua compreensão: processo, eficiência, prazos e metas" (CARVALHO, 1979, p. 14).

Sob essa abordagem, o planejamento caracteriza-se por um processo sistematizado. A efetivação do planejamento considera as etapas que o constitui, garantindo o feedback ao longo do processo.

Com base nas linhas diretivas de ação escolar, existem alguns níveis de planejamento, afirma Carvalho (1979). a) Planejamento Educacional: Este planejamento abrange um nível mais amplo, prevendo a estruturação e o funcionamento do sistema educacional como um todo. As autoridades educacionais estão a cargo do Ministério da Educação, Conselho Nacional de Educação e órgãos Municipais, Estaduais. Contase também com os Conselhos Estaduais de Educação, 
os quais exercem sua competência nos estabelecimentos vinculados ao poder público estadual ou municipal, já referenciado anteriormente.

De acordo com Vasconcellos (2013) o planejamento de ensino é "previsão inteligente e bem calculada de todas as etapas do trabalho escolar que envolvem as atividades docentes e discentes, de modo a tornar o ensino seguro, econômico e eficiente" (1968, p.140), acrescentando a definição de Cappelletti (1999) como "a previsão das situações específicas do professor com a classe" (p, 10). Pode-se dizer então que o ato de planejar suas ações acompanha o homem desde o início de sua existência, pois a história dele é resultado do presente e do passado, ou seja, ao procurar satisfazer suas necessidades o homem produziu diferentes relações, dentre elas, as educativas.

Luckesi (2011) conceitua o planejamento como "a atividade intencional pela qual se projetam fins e se estabelecem meios para atingi-los. É uma ação ideologicamente comprometida e não possui caráter de neutralidade" ( p. 117). Por isso o planejamento será um ato ao mesmo tempo políticosocial, científico e técnico. Ao realizar o planejamento na escola não basta que o professor apenas esteja atento aos meios, faz-se necessário também os fins, os objetivos da educação.

Um aspecto importante a ser lembrado é que o professor não pode perder de vista que a escolha das metodologias está articulada aos princípios e finalidades da educação, por ele preconizado. Tal procedimento é importante, visto que as metodologias possuem fundamentação político filosófica, portanto não se constitui um elemento neutro. Enfim, não se pode esquecer que a escola necessita desenvolver o seu trabalho pedagógico, em longo prazo, com objetivos a serem atingidos no bimestre, semestre ou no ano letivo. Mesmo que isto seja difícil num país em que não se tem clareza política e econômica do que vai ocorrer amanhã, este argumento não pode ser utilizado para que a escola planeje somente para o dia seguinte.

Planejar implica preocupar-se com a aprendizagem, com a obtenção do conhecimento e como ninguém pode dar o que não tem, como ajudar alguém para conhecer sem se ter o conhecimento? O domínio do conteúdo é a base sólida que vai determinar se o trabalho é coletivo ou não. Desta maneira, o planejamento 
implica discutir a questão como diz Pinto (2010), sobre o conteúdo e a forma da educação.

\section{PROFESSOR E ALUNO NO PROCESSO DE APRENDIZAGEM}

Atualmente, são exigidas algumas habilidades aos professores, como: formar indivíduos com uma visão mais global da realidade, vincular a aprendizagem a situações e problemas reais, preparar o aluno para aprender durante toda a vida.

[...] formar para a vida significa mais do que reproduzir dados, denominar classificações ou identificar símbolos. Significa: saber se informar, comunicar-se, argumentar, compreender e agir; enfrentar problemas de diferentes naturezas; participar socialmente, de forma prática e solidária; ser capaz de elaborar críticas ou propostas; e, especialmente, adquirir uma atitude de permanente aprendizado (PCNEM, 2002, p.9).

O trabalho com projetos muda o foco da sala de aula do professor para o aluno, da informação para o conhecimento, da memorização para a aprendizagem. Equilibra teoria e prática, divide responsabilidades e tarefas, comunica resultados, discute processos avaliativos. Ao trabalhar com projetos, professor e aluno assumem a condição de pesquisadores e co-responsáveis pelo processo de aprendizagem.

Situações problemas são levantadas para aproximar a aprendizagem de situações reais vividas pelos alunos. Hipóteses são discutidas e testadas para se chegar a soluções possíveis à compreensão dos alunos. O trabalho com pesquisa, que perpassa todas as etapas de um projeto, favorece que a informação se transforme em conhecimento e aprendizagem.

De acordo com Hernández (2000) o professor deve ser um pesquisador, abandonando a partir desta concepção o papel de transmissor de conteúdos, saindo de receptor passivo a sujeito do processo. Isto quer dizer que, não existe receita pronta em relação à utilização da metodologia de ensino por projetos.

$\mathrm{Na}$ pedagogia de projetos $\mathrm{O}$ aluno aprende durante o processo a levantar dúvidas, buscar soluções para os problemas levantados, construir e reconstruir o conhecimento. Neste processo, são criadas situações de aprendizagem cabendo ao professor realizar mediações necessárias para que o aluno consiga encontrar 
sentido, significado naquilo que está aprendendo, a partir das relações criadas nessas situações.

De acordo com Valente:

(...) no desenvolvimento do projeto o professor deve trabalhar com [os alunos] diferentes tipos de conhecimentos que estão imbricados e representados em termos de construções: procedimentos e estratégias de resolução e problemas, conceitos disciplinares e estratégias e conceitos sobre aprender. (VALENTE, 1999, p. 4).

Segundo Barbosa (2003) a metodologia de projetos se caracteriza por um instrumento que favorece a aprendizagem criando situações que possibilitem a formação de um ciclo de progresso, neste mesmo processo.

Considerando que a situação-problema é o objetivo do projeto, as ações e os conhecimentos necessários para a compreensão são discutidos e planejados entre o professor e os alunos. Além disso, todos têm tarefas e responsabilidades. Quando os alunos são estimulados a resolver situações-problema, interessam-se mais pelo assunto em questão, participam de forma intensa na busca de novas informações sobre o conteúdo, sentem-se úteis e, dessa maneira, a aprendizagem é, de fato, almejada.

A metodologia de ensino por projetos possibilita uma antecipação coletiva e formal das fases que caracterizam o seu desenvolvimento e dos objetivos a serem alcançados, e isso podemos conseguir por meio de uma discussão flexível que permita reorganização, caso for necessário.

Behrens (2000b, p. 94) salienta que "como sujeito, o aluno precisa ser instigado a avançar com autonomia, a se exprimir com propriedade, a construir espaço próprios, a tomar iniciativa, a participar com responsabilidade, enfim, a fazer acontecer e a aprender a aprender"

Leite, Malpique e Santos (1993, p. 68), descrevem esse aspecto da seguinte forma:

o aluno só aprenderá quando tiver prazer em conhecer, ou seja, quando tiver uma curiosidade livre de bloqueios (...) O professor só conseguirá ensinar quando tiver prazer na sua ação catalisadora da curiosidade dos seus alunos, mantendo, porém, a objetividade na apreciação que deles deverá fazer. 
Os professores que utilizam esta metodologia precisam ser profissionais que reflitam sobre suas próprias ações pedagógicas

Para Donald Schön (2000, p. 32), "quando aprendemos a fazer algo, realizamos a tarefa sem pensar muito a respeito, somos aptos a nos impulsionar espontaneamente à realização das tarefas, nem sempre sendo dessa forma". Todas as experiências, sejam agradáveis ou não, contêm um elemento de surpresa, quando algo não está de acordo com as expectativas, pode-se responder à ação colocando a situação de lado, ou responder a ela por meio da reflexão, tendo esse processo duas formas: refletir sobre a ação, examinando retrospectivamente o que aconteceu e tentando descobrir como nossa ação pode ter contribuído para o resultado, ou refletir no meio da ação, sem interrompê-la,chamando esse processo de reflexão-na-ação.

Nesse momento, pode-se dar uma nova forma ao que está fazendo enquanto ainda está fazendo, portanto refletindo-na-ação.

Esse processo de reflexão auxiliará na condução da aprendizagem do aluno. A ação docente deve provocar processos que permitam conseguir compreender e interpretar os temas apresentados, deixando claro o objetivo ou o significado de porque está se originando nesse processo a produção de novos conhecimentos.

\section{METODOLOGIA DE ENSINO POR PROJETOS}

De acordo com Leite (2007), o aluno quando participa de uma metodologia de ensino por projetos envolve-se numa experiência educativa em que o processo de construção e reconstrução do conhecimento está integrado às práticas vivenciadas. Ainda segundo o autor, o estudante deixa de ser apenas um aprendiz do conteúdo para transformar-se em um ser humano capaz de desenvolver uma atividade complexa e nesse processo apropriasse de um objeto de conhecimento cultural.

Antunes (2012) define projeto como uma pesquisa ou uma investigação desenvolvida com profundidade sobre um tema ou um tópico que se acredita importante conhecer. O objetivo de um projeto para este autor é o esforço investigativo voltado a encontrar respostas corretas, abrangentes e a aprender de forma significativa o tópico estudado. Para Martins (2015) a implementação da 
"Metodologia de Projetos" contribui para que o aluno participe e se envolva no seu próprio processo de aprendizagem compartilhando com os colegas, exigindo que o professor enfrente desafios de mudanças para diversificar e reestruturar de forma mais aberta e flexível os conteúdos escolares.

Segundo Martins (2015), as vantagens de incrementar o ensino por meio de projetos de trabalho serão logo sentidas após as primeiras experiências, quando o professor e mesmo as famílias perceberão:

a) a motivação dos alunos na busca de informações e dados;

b) a interação e a troca de experiências entre eles, assim como compartilhar responsabilidades entre os grupos;

c) as transformações sentidas nas salas de aula;

d) o despertar das questões sobre os fatos ou problemas que estão sendo estudados querendo saber mais sobre o assunto e a vontade dos alunos de querer mostrar aos demais colegas da escola os resultados alcançados por meio de seminários, pôsteres, murais, e outras formas de comunicação.

A metodologia de projetos segundo Hernández (1998), articula os conhecimentos escolares proporcionando organizar a atividade de ensino e a aprendizagem.

Vasconcellos (2013. p. 160) defende que:

A maneira de se fazer o projeto pode ser fruto de uma aprendizagem coletiva, através da troca de experiências e de uma reflexão critica e solidária sobre as diferentes práticas. É preciso compreender onde é que o grupo está, quais suas necessidades. Ou seja, na busca de mudança do processo de planejamento, o ideal é a coordenação construir a proposta do roteiro de elaboração do projeto junto com professores; se não for ainda possivel, pode propor, justificar mostrar como aquele roteiro pode ajudar o professor a fazer um bom trabalho.

Porém, uma das características mais importante do projeto é a autonomia. É por essa razão que quando o projeto surge dentro de uma necessidade da sala de aula, aumenta a qualidade do conteúdo e cria a possibilidade da obtenção de melhores resultados. 


\section{CONCLUSÃO}

De acordo a bibliografia consultada, fica evidente que a metodologia de ensino por projetos supera a perspectiva de acumulação e memorização de informações. Considerando que o conhecimento está em constante transformação, a oportunidade de diversificar as atividades metodologicamente propicia maneiras diferentes de aprendizagem. Trata-se de uma aprendizagem pluralista, de conexões, relações e contextualização, criticidade diante de informações, de desenvolvimento individual e coletivo

É importante que professores e alunos estejam conscientes sobre os objetivos que se quer alcançar com o projeto e cabe ao professor estar sempre a par de cada procedimento do projeto para que se possa atingir o objetivo.

O trabalho com projetos é um recurso pedagógico útil para mobilizar naturalmente as diversas competências cognitivas. Entende-se também que o planejamento e a integração de disciplinas, adaptados ao currículo, favorecem a aplicabilidade de conteúdos por meio da metodologia de projetos.

\section{REFERÊNCIAS}

ANTUNES, Celso. Um método para o ensino fundamental: o projeto. 5a.ed. Petrópolis, RJ: Vozes, 2012.

BARBOSA, Laura Monte Serrat. O projeto de trabalho: uma forma de atuação psicopedagógica. Curitiba: Arins LTDA, 2003

BEHRENS, Marilda Aparecida. Projetos de aprendizagem colaborativa num paradigma emergente. In: MORAN, José Manuel; MASETTO, Marcos Tarcísio; BEHRENS, Marilda Aparecida. Novas tecnologias e mediação pedagógica. Campinas, SP: Papirus, 2000.

CAPELLETTI, I.F. Planejamento de Ensino. Revista Escola, São Paulo,173 n.5, 1999.

CARVALHO, Horácio de. Introdução à teoria do planejamento. São Paulo: Brasiliense, 1979.

HERNÁNDEZ, Fernando.; VENTURA, M. A organização do currículo por projetos de trabalho: o conhecimento é um caleidoscópio. 5 ed. Porto Alegre: Artes Médicas, 2000 
LEITE, Lúcia Helena Alvarez, Pedagogia de Projetos: intervenção no presente. Presença Pedagógica, Belo Horizonte: Dimensão, 2000.

LEITE, Elvira; MALPIQUE, Manuela; SANTOS, Milice Ribeiro dos. Trabalho de projeto: leitura comentada. Porto: Afrontamento, 1993.

LUCKESI, C. C. Planejamento e avaliação na escola: articulação e necessária determinação ideológica. In: O diretor articulador do projeto da escola. BORGES, Silva Abel. São Paulo, 2011. FDE. Diretoria Técnica. Série Idéias nº 15.

MARTINS, Jorge Santos. O trabalho com projetos de pesquisa: do ensino fundamental ao ensino médio. 8a.ed. Campinas, SP: Papirus, 2015.

SCHÖN, Donald. Educando o Profissional Reflexivo: um novo design para o ensino e a aprendizagem. Porto Alegre: Artes Médicas Sul, 2000

VALENTE, José Armando (Org.). Formação de Professores: Diferentes Abordagens Pedagógicas. In: VALENTE, José Armando. O computador na Sociedade do Conhecimento. Campinas, SP: UNICAMP-NIED, 1999.

VASCONCELOS, Celso dos Santos. Construção do conhecimento em sala de aula. São Paulo. Libertad, 2013 